\title{
Fine Red Threads: Dislocation and Identity in Lisa Bird-Wilson's Just Pretending
}

\section{Alison Calder}

\section{(2) OpenEdition}

1 Journals

Electronic version

URL: https://journals.openedition.org/ces/2207

DOI: $10.4000 /$ ces.2207

ISSN: 2534-6695

Publisher

SEPC (Société d'études des pays du Commonwealth)

\section{Electronic reference}

Alison Calder, "Fine Red Threads: Dislocation and Identity in Lisa Bird-Wilson's Just Pretending", Commonwealth Essays and Studies [Online], 42.2 | 2020, Online since 30 September 2020, connection on 20 January 2022. URL: http://journals.openedition.org/ces/2207 ; DOI: https://doi.org/10.4000/ces 2207

This text was automatically generated on 20 January 2022.

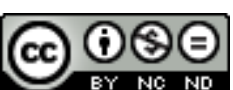

Commonwealth Essays and Studies is licensed under a Licence Creative Commons Attribution - Pas d'Utilisation Commerciale - Pas de Modification 4.0 International. 


\title{
Fine Red Threads: Dislocation and Identity in Lisa Bird-Wilson's Just Pretending
}

\author{
Alison Calder
}

The official territorial acknowledgement of the University of Manitoba begins by stating where we are: Treaty One territory, the traditional lands of the Anishinaabeg, Cree, Oji-Cree, Dakota and Dene peoples, and the homeland of the Métis nation. While this is an acknowledgement of fact, the final phrase, "the homeland of the Métis nation," enters into heated current discussions about who, in fact, is Métis, and where that identity is located. According to Statistics Canada, "the number of people calling themselves Metis soared nearly 150 per cent in Quebec and 125 per cent in Nova Scotia from 2006-2016," and "dozens of new Metis organizations cropped up over the same period" (Bundale 2018). ${ }^{1}$ This rise, based on individual self-identification and tenuous genealogical research, coincides with court rulings guaranteeing Métis people hunting rights and other "benefits." 2 Against such individual claims, the struggles of Métis people in Western Canada for recognition and reconciliation emphasize the importance of kinship and community in determining identity and belonging. My consideration of Métis writer Lisa Bird-Wilson's short story collection Just Pretending picks up these two strands: what home is, and what it is to be Métis. Both of these questions permeate Bird-Wilson's stories, and are continually linked in ways that show them to be inseparable. These stories contribute to current discussions of how Métis-ness is defined by suggesting that genetics is not enough, and that Métis-ness has to incorporate kinship as well as genealogy. The "fine red threads" that Bird-Wilson describes and creates are not only veins, but also storylines connecting and strengthening both individuals and the community in the creation of a meaningful homeland.

Daryl Leroux's 2019 study of self-Indigenizing French descendants in New France, Distorted Descent: White Claims to Indigenous Identity, clarifies what is at stake in suggesting that one can be Métis by virtue of genealogy alone. Leroux finds that race shifting, the practice of white settlers claiming Indigenous or Métis identity based on a 
single ancestor located as far back in time as 1604 , is predominantly mobilized in order for white settlers to challenge Indigenous land claims and rights. "It is above all a twenty-first-century effort to transform the boundaries of whiteness and white identities in a context where Indigenous political claims risk undermining the established (white) order of things. In that sense, race shifting facilitates white futurity in response to conventional reconciliation frameworks" (2019, "Conclusion"). By selfidentifying as Indigenous based solely on genealogy, race shifters claim the right to speak for, as, and against Indigenous people. While self-recognition as an Indigenous person is an important aspect of reclaiming an identity lost because of forced adoption, dispossession, residential schools, or other colonial traumas, it is but one aspect of a much larger complex, as articulated in the Manitoba Métis Federation's Constitution: "Métis means a person who self-identifies as Métis, is of historic Métis nation ancestry, is distinct from other Aboriginal Peoples and is accepted by the Métis nation" (Manitoba Métis Federation 2015). Maria Campbell specifies that Métis identity is descended from the communities whose lands were taken by the Canadian government following "the Métis resistances of 1869-70 in Red River and 1885 in Batoche. These events led to the dispossession of the Métis and Halfbreeds from there and created a diaspora that is the source of the poverty, rootlessness, and loss of identity being experienced by Métis people today" (2012, XIII-XIV). This communal experience of displacement and its aftermath, taking place over generations, is often articulated in terms of Métis nationalism, as seen in the University of Manitoba's territorial acknowledgement. As MacDougall, Podruchny, and St-Onge write in Contours of a People, "Having an Indian ancestor does not make one Métis; rather, Métis people emerged in and descended from communities of dual heritage with common interests and goals" $(2012,4)$. What makes a Métis collective consciousness, they write, is the confluence of "three elements - geography, mobility, and family" (6). Jennifer Adese makes a similar argument, writing that identifying Métis-ness solely on the basis of "mixed blood,"

creates confusion that more often than not sees Métis-ness divorced from its roots as a collective identity. It is instead refashioned as an identity that people can elect to adopt for the pursuit of individual self-interest. It obscures that although métis as a word exists as a fact of French language, it was through a complex interplay of cultural, social, economic, and political transformations that it became the identifier of choice of a distinctive Indigenous people. $(2016,260)$

Speaking from personal experience, Adese goes on to clarify that one does not have to be raised in a Métis community with full knowledge of family and cultural practices, but that it is possible for someone, through much work, to come to these connections later in life. There are many reasons, usually as a result of colonialism, that kinship and communal relations (both local and more broadly conceived) may be severed. However, they need to be brought together and recognized as mutually constitutive elements of Métis emplacement; genetics alone is not enough.

Concern with the three elements identified by MacDougall, Podruchny, and St-Onge geography, mobility, and family - as characteristic of Métis identity resonates through Bird-Wilson's collection, and is especially refracted through the lens of homelessness. Bird-Wilson's characters occupy dangerous, uncomfortable, and precarious spaces: prisons, violent family homes, party houses, the streets. Some characters do have houses, but only because of the domestic relationships they endure, while others live with adopted families who resent or belittle them. Each of these precarious home situations is predicated on the failure or rupture of kinship connections, often resulting from the government practice of adopting or selling Indigenous and Métis children to 
White families (this is called the Sixties Scoop). ${ }^{3}$ The homelessness or precarious housing experienced by Bird-Wilson's characters is a reflection of an ontological homelessness in a much wider sense. A 2012 definition of Indigenous homelessness from the Aboriginal Standing Committee on Homelessness is helpful in articulating what this means:

Indigenous homelessness is a human condition that describes First Nations, Métis and Inuit individuals, families or communities lacking stable, permanent, appropriate housing, or the immediate prospect, means or ability to acquire such housing. Unlike the common colonialist definition of homelessness, Indigenous homelessness is not defined as lacking a structure of habitation; rather, it is more fully described and understood through a composite lens of Indigenous worldviews. These include: individuals, families and communities isolated from their relationships to land, water, place, family, kin, each other, animals, cultures, languages and identities. Importantly, Indigenous people experiencing these kinds of homelessness cannot culturally, spiritually, emotionally or physically reconnect with their Indigeneity or lost relationships. (Thistle 2017)

So what, then, might be an expression of Indigenous "home"? One answer to "home" is suggested in Richard Wagamese's novel Keeper 'n Me (1994), in which the protagonist, Garnet French, has been taken from his birth family as part of the Sixties Scoop, and raised to despise the idea of Indigeneity. When the novel opens, he is living in Toronto, adopting various ethnicities as his own - Hawaiian, Japanese, Black - before returning to his birth family and territory and discovering what it means to be Indigenous. Realizing that his mother's heartbeat and the heartbeat of the earth are one and the same, Garnet is able to move into relationship with land and family, and to receive powerful visions. Rediscovering his kin relationships can only fully happen in this particular spot as he discovers traditional knowledge and returns to his proper place. Although Garnet maintains connections to an urban setting - his interest in bringing radio to the reserve is an indication of this - we see his healing process in terms of his relation to the land. A similar connection between land and Indigeneity features in the novel Moon of the Crusted Snow (2018) by Waubgeshig Rice, which is set on an isolated reserve in northern Ontario. When the world's power grid is knocked out, southern cities are sites of mayhem and murder, but Indigenous people who live on the reserve in traditional ways are able to survive and ultimately to repel the threats represented by outsiders. Members of the reserve community who rely on colonial infrastructure such as electricity, canned food, and alcohol, are vulnerable to exploitation and ultimately to death. Both Rice's and Wagamese's novels underscore the importance of land and land-based knowledges in understanding, and surviving, as Indigenous people.

But what if you don't have land to return to? I want here to turn to a recent article by Métis scholar Aubrey Hanson on Katherena Vermette's 2016 novel The Break, which is set in Winnipeg and which, like most of Bird-Wilson's collection, focuses on Métis and Indigenous women living in violent urban environments. Keeping in mind the definition of Indigenous homelessness outlined by the Aboriginal Standing Committee, I want to look at how Hanson sees its opposite, home, articulated in Vermette's novel. Hanson begins by positioning herself, writing that "in my own experience as a Métis woman, home is affective and relational, not merely a static sense of place" $(2019,27)$. Describing her feelings of grief when her grandparents sold their house, she writes "I had not realized consciously that while I lived in many places I was deeply at home in that house, and, even deeper than that, I was at home in my connections with my kin" (28). Finally, she describes her late grandmother: "her eyes bright, her voice laughing, 
her hands baking, her mind always weaving the past with the present, the there with the here, constantly narrating for us how things were and might be. When she died, I learned that that was home" (28). Reading Vermette's novel, she finds articulated this "home" in the kinship connections between Vermette's characters, connections that give the characters resilience in the face of a terribly violent act. "It is significant," she writes,

that the Métis women in The Break are finding home-an ongoing, relational process

-in their webs of kinship: holding home together is what enables them to endure, to be resilient. A focus on urban Indigenous women's resilience works to undermine the colonial notions that frame Indigenous women's bodies as being out of place in cities and as natural targets of violence. (42-43)

Bird-Wilson's collection shows the same kind of violent urban reality, though many of her characters have experienced disruption of or utter disconnection from any family connections. ${ }^{4}$ Her characters also have few traditional connections to the land to return to. The closest Bird-Wilson comes to depicting a return to the land is in the stories "Ayekis" and "Lost." In "Ayekis," the young narrator visits her Cree grandparents in the bush, but her inability to fit into this environment is signaled by her having to "camp on the couch" $(2013,167)$. Though her local cousins speak Cree and make fun of her by calling her "moonias" (white person), she herself turns out to be more alive to cultural traditions and sensitive to the non-human world than her brutal cousin, Kyle, who tortures a frog to death. The frog's torment clearly shows that Kyle has lost any connection with the non-human environment. In "Lost," the narrator, Sunny, and her little brother do camp in the woods with their family, but as the title suggests, they get lost. Sunny tries to entertain her brother in various ways, including by pretending to be a tour guide and adopting an Italian accent that turns Transylvanian (197). Her failure to play the role of guide points ironically to her failure to play another, larger, role, that of the wise dweller of the woods often expected of Indigenous people. Though the story has a positive resolution - the children are found - it is obvious that this time in the woods has not clarified Sunny's larger questions: as the search party leaves the forest, she writes, "an owl asked us its relentless question again and again" (206). The title of Bird-Wilson's book, Just Pretending, is indicative of the fears of many of her characters: that they are "just pretending" to be someone. In the story "Someone's Been Lying to You," the narrator muses over the insults she has hurled at her erstwhile boyfriend, Jerry: "I knew calling him Apple would bother him because of his background, being adopted and all - red on the outside, white on the inside. He's pretty sensitive that way. Wants to fit in with us, and yet there's something about him something a bit off. Like everyone can tell that he spent his life living like a white guy" (24). Later, though, it turns out that the narrator is likewise uncertain about her own identity, writing a story called "I'm a Potato," and realizing that the reason her mother never took her and her sister "up north" was not because "she didn't want us to act like Métis, didn't want us to know our culture" (25), but because "she knew how we'd be treated, that people would call us Apples, accuse us of being moonias" (26). Including a retelling of the forced displacement of this Métis community from south to north, made to watch as "their homes [were] doused with gasoline and set to burn" (25), situates the unsettled condition of the narrator, Jerry, and many other characters within a continuum of forced relocation and trauma.

"Blood Memory" is the first extended narrative in Bird-Wilson's collection, and it describes the experience of displacement from place and kinship in a most 
fundamental way: displacement from the mother's body. The story details both abandonment and relationship, as the pregnant narrator imagines her own mother's pregnancy. These experiences oppose each other in every way: the mother's pregnancy is unwanted, while the narrator looks forward to her child's birth; the mother is lodged in a home for unwed mothers, hostile and punitive, while the narrator is able to give birth in her own bathtub, surrounded by midwives and caring family; the narrator is born into an experience of abandonment, as she is immediately given up for adoption, while her own baby is born into and is the foundation for a web of kin. It is important to note that the narrator's mother's experience is entirely imagined by the narrator and the mother's real voice is never heard. For the narrator, her mother's pregnant body becomes a highly conflicted site in which the unborn narrator is both an aggressor (as when she is figured as a parasite inhabiting her mother's reluctant body) and a victim of abandonment and even attempted murder (as when her mother electrocutes herself with the toaster, endangering the narrator). This is indeed precarious housing, emphasized by a series of violent images: in the narrator's mind's eye, her mother sees herself as an overstuffed olive to be eventually popped with a fork, or imagines using "gigantic garden shears sharpened to a razor's edge" to cut the umbilical cord binding her to the "silent sea monster in the well of her incubator body" (Bird-Wilson 2013, 5). Meanwhile, the baby-narrator is described as "trying desperately to escape as a muskrat will chew its own leg off to get out of a trap" (5). The rejection of the fetus through this violent imagery continues after birth, as the physical expulsion of the baby from the mother is echoed in the mother's refusal to fill out adoption information forms in any other than the most perfunctory way. The narrator remarks that her mother "fills in the blanks as best she can - there are rules about these things - but no one can make her open her heart, and no one can force her to leave anything behind, not even a name" (9).

If the maternal body is a dangerous container, so too is language. The narrator's mother has left her only one word on which to base her identity: Métis. This Métis-ness seems resolutely biological, a "hereditary condition" (Bird-Wilson 2013, 5) that the narrator includes as part of her medical history. It is figured with a materiality that carries weight: Métis is "a word waiting to be picked up and held in the palms of two hands examined then crushed to the chest rubbed into arms, over shoulders, across the belly, the word more than a word, to be inhaled then expelled bit by bit with every breath" (4). Rather than nourishing the narrator, the word "Métis" only points the narrator towards loss: "I'm teetering on the edge of an insurmountable regret, a loss so large it threatens to smother me - the loss of what was mine by birth, a deficit that I wear like a scar" (6). "Métis," a word initially introduced with such sensual imagery, becomes double-edged. Rubbing it over the body causes physical damage, the narrator's "scar," as embedded within the identifier is also always a gap that emphasizes the mother/daughter separation.

Métis identity, repeatedly figured biologically as a kind of "blood memory," seems solid, a physical thing to be lost, something granted by birth and located in the body. But the trickiness of language kicks in, as words and labels become flexible despite attempts to fix or solidify them. The story's concern with language and its effects is shown on multiple levels, perhaps most clearly in the ways that the narrator's mother repeatedly tries to disconnect herself from her pregnancy by refusing the word "baby," explicitly and emphatically insisting on "fetus fetus fetus" (Bird-Wilson 2013, 5; original emphasis). The relation of language to identity becomes clear in the punning 
description of the mother's time in the home for unwed mothers as a "sentence" during which "shameful words creep up on her" (8). These words, both English and Cree, identify the mother as wrong and disgraceful, as "macitwawiskwesis, a bad girl" (8). But while these identifiers attempt to fix the subject's identity, allowing the bodies of both the pregnant mother and the unwanted fetus to be disposed of, these words are not entirely successful. That the narrator's mother is "macitwawiskwesis" does not cancel out the possibility that she is also "nitânis," daughter, and the failure of her attempt to distance herself from the fetus is revealed when she dreams. She dreams of finding a jewellery box that transforms itself into a bomb, and attempts to defuse it by saying the mock-magic word "ababa." As the jewellery box/ticking time bomb represents the mother's pregnant body, we can see the dream's other "truth" revealed in the mother's speech, in which "ababa" is both a variation of "abracadabra," and "a baby." The word reveals and masks at the same time.

While the label "Métis" appears to firmly indicate an identity, it functions in somewhat the same way as "ababa," which seems to provide a solution at the same time as it is incomplete, invoking and displacing meaning simultaneously. While in this story the idea of Métis-ness cannot be separated from the body, the story also suggests that Métis-ness can be at least partially recovered through a kind of self-construction, and here again language is key. While the narrator begins the story alienated from the maternal body and from a web of Métis kin, she does not end the story like this. "I can't shake the dream-world mother I've created," she writes, and this connection, though invented, allows her finally to be called "nitânis" (Bird-Wilson 2013, 9). This maternal recognition is inextricable from grief, though, as the narrator writes, "I'm confused and angry over the loss of what I needed: identity, blood inheritance, to be Métis, to know where I've come from, something to pass on to my own child, who will also be blind to what ought to be hers by birth" (9). This "blindness" recalls the mother's earlier refusal to "see" the narrator as her daughter, naming her only as "fetus," "sea monster," "tadpole," and "it."

The short, final paragraph of this story counters much of the dislocation and precarity that has gone before, as the establishment of a bond between the narrator and her baby situates them both in a web of kinship that is predicated on, but not limited to, biological connection. Again the self-reflexive punning on "sentence" pulls together issues of identity, loss, and language. In the narrator's arms, her baby is "Curled like a comma, punctuation, an exclamation: the end of a sentence, making way for something new" (Bird-Wilson 2013, 9). Held in her arms, the narrator writes, the baby "looks at me - looks and looks - her eyes wide and serious" (9). This intense look, that sees the narrator, counters the blindness suggested in the previous paragraph, as "what ought to be hers by birth" is revealed to both mother and daughter. If we understand homelessness as the profound displacement from kinship structures, then we can see here the beginnings of an emplacement that situates both mother and daughter in relation to each other, a connection that acknowledges loss but also sits alongside it as a source of strength. This simultaneity is fully reflected in the story's final sentence, in which the narrator realizes her daughter is her "first blood relation" (9). If "relation" is read in the double sense of both noun and verb, as biological relative and as storytelling (to relate a story), then this recognition and emplacement incorporates both genetics and community in its assertion of Métis identity. Telling a story, a process requiring a reciprocal relationship between teller and audience, is a vehicle that moves 
the narrator's attachments from the past ("blood memory") to the present and future ("blood relation"), while still keeping all of these elements in play.

The complications of place and relationship are articulated from another perspective in the story "Billy Bird," which is sort of a bookend to "Blood Memory" as it takes place in a nursing home (another kind of temporary, institutional housing, like the home for unwed mothers in "Blood Memory"). The adult protagonist, Billy, visits his grandfather, who is suffering from advanced dementia and its complications. Though the grandfather's body is exposed to view, he himself remains a cipher that Billy cannot read, another sign that appears to explain something but, in isolation, actually does not. For Billy, his grandfather's presence in this deteriorated state is a reminder of all that he will never know:

Billy's been mad at his Mooshum for twenty years for not being able to tell him the stories.

Tell me who I am Mooshum, Billy thinks.

A Mooshum should tell his grandson the stories. (Bird-Wilson 2013, 187)

Billy's anger recalls that of the narrator in "Blood Memory," and again, Bird-Wilson's imagery imbricates genealogy and kinship. Without story, without that "affective and relational" connection (Hanson 2019), Billy is adrift:

Billy sees himself as part of a circle, part of a never-ending circle he shares with the grampas and grannies of his past. Each of them holds a fine red thread that reminds him of a fresh-spun spider silk, but a red one, and one that can't be broken. His whole family is there sharing the circle with him, people he looks like, people he's connected to, people whose traits he shares, people whose history is his own, grannies and grampas, Nêhiyaw and Métis, all connected by that silky red thread. (Bird-Wilson 2013, 186)

After Mooshum's death, the text again picks up on the image of the red threads, this time in a physical sense: "the lids of Mooshum's eyes are still, no longer mapping the fine red stream of veins, the ruby tendril threads" (191). These red threads, which Billy has previously seen in his own hand when he put a flashlight behind it, represent a physical connection between the generations - but they also represent those larger connections and relationships figured as a spiderweb that tells Billy who he is. Though one kind of connection is broken with his Mooshum's death, Billy remains part of this larger circle, which his Mooshum is still part of too. In this way, we can understand place as composed of relationships: Bird-Wilson's Métis characters may be homeless, but some of them are able to make connections, however partial, that suggest they can make their own ground to stand on.

"It is far easier," writes Leroux, "to develop a so-called Métis identity through genealogy than it is to re-establish relations (if and when they exist) in a matrix of accountability to Indigenous peoples" (2019, Chapter One). The importance of family and community connections in Just Pretending points to the hard work involved in claiming a spot in the Métis Nation. "Home" is located not simply in genetics nor in geography, but in the complicated and simultaneous relationships between people and place, which must be continually renegotiated and strengthened. Bird-Wilson's collection honours these relationships and the people who work, sometimes against tremendous odds, to build or rebuild them. 


\section{BIBLIOGRAPHY}

ADESE, Jennifer. 2016. “The New People: Reading for Peoplehood in Métis Literatures.” Studies in American Indian Literatures 28, no. 4: 53-79.

BIRD-WILSON, Lisa. 2013. Just Pretending. Regina: Coteau.

BUNDALE, Brett. 2018. "We're reclaiming our heritage: the controversial rise of the eastern Metis." https://www.cbc.ca/news/canada/nova-scotia/the-controversial-rise-of-the-eastern-metiswhere-were-these-people-all-this-time-1.4680105.

CAMPBELL, Maria. 2012. "Foreword: Charting the Way." In St-Onge et al., XIII-XXVI.

HANSON, Aubrey Jean. 2019. “Holding Home Together: Katherena Vermette's The Break.” Canadian Literature 237: 27-45.

LEROUX, Darryl. 2019. Distorted Descent: White Claims to Indigenous Identity. Winnipeg: University of Manitoba Press. Kindle.

Manitoba Métis Federation. 2017. "Manitoba Métis Federation Inc. Constitution.” http:// www.mmf.mb.ca/docs/mmf_constitution2017.pdf.

"Métis Nation Rights." n.d. Métis National Council. www.metisnation.ca/index.php/who-are-themetis/rights.

RICE, Waubgeshig. 2018. Moon of the Crusted Snow. Toronto: ECW Press.

Indigenous Foundations. 2009. "Sixties Scoop." University of British Columbia First Nations and Indigenous Studies. https://indigenousfoundations.arts.ubc.ca/sixties_scoop/.

ST-ONGE, Nicole, Carolyn PODRUCHNY, and Brenda MACDOUGALL, eds. 2012. Contours of a People: Métis

Family, Mobility, and History. Norman: University of Oklahoma Press.

THISTLE, Jesse. 2017. “Definition of Indigenous Homelessness in Canada." https://

www.homelesshub.ca/IndigenousHomelessness.

WAGAMESE, Richard. 1994. Keeper ' $n$ Me. Toronto: Anchor Canada.

\section{NOTES}

1. "Métis" is the spelling used by the Métis Federation of Manitoba and I use it in this paper to indicate Métis people with historic attachment to the Red River community. Metis, without the accent, indicates "new" Metis people from Quebec and Nova Scotia. All quotations use the spelling that exists in the original source.

2. Métis rights and title were extinguished in 1870 by an Act of Parliament. In recent years, key court decisions have "recognized and affirmed the existence of Métis as a distinct aboriginal people with existing rights" (Metisnation.ca). These rights, which may include such things as government support or subsidy of health care or education, or the ability to contest land claims, are often perceived by the wider public as benefits that Indigenous people are given "for free." Such beliefs, based in racism, ignore historical fact.

3. This phrase "sixties scoop" refers to the mass removal of children from Indigenous homes and their placement through adoption or fostering in non-Indigenous families. This removal was enacted disproportionately in Indigenous communities. According to Indigenous Foundations, 
"By the 1970s, roughly one third of all children in care were Aboriginal. Approximately 70 percent of the children apprehended were placed into non-Aboriginal homes, many of them homes in which their heritage was denied" (2009).

4. It is possible to see ideas of disruption enacted through the structure of the collection. While the stories have a strong thematic unity, there are twenty-four separate pieces in the book, some very short, and all with different characters and settings. Some pieces vary considerably in tone because they include elements of traditional Indigenous oral culture, such as the presence of Wesakechak, a trickster figure. They do not show the formal unity of a traditional novel.

\section{ABSTRACTS}

This paper examines Canadian Métis author Lisa Bird-Wilson's short story collection Just Pretending in light of "race shifting" as identified by Darryl Leroux in Distorted Descent. Against a model of Métis identity that is based purely on distant genealogical connections and selfidentification, Bird-Wilson's collection suggests that Métis identity is inseparable from community relationships and responsibilities. Images of "fine red threads" in these stories refer not only to veins, but also to storylines that can counter dispossession and homelessness.

\section{INDEX}

Keywords: Lisa Bird-Wilson, Canadian literature, Métis literature

\section{AUTHOR}

\section{ALISON CALDER}

University of Manitoba

Alison Calder is a Professor in the Department of English, Theatre, Film \& Media at the University of Manitoba, where she teaches Canadian literature and creative writing. She has published widely on prairie literature and culture, and is an award-winning poet. 